\title{
BMJ Global Health Effectiveness of participatory Women's groups scaled up by the public health system to improve birth outcomes in Jharkhand, eastern India: a pragmatic cluster non-randomised controlled trial
}

Nirmala Nair, ${ }^{1}$ Prasanta K Tripathy, ${ }^{1}$ Rajkumar Gope, ${ }^{1}$ Shibanand Rath, ${ }^{1}$ Hemanta Pradhan, ${ }^{1}$ Suchitra Rath, ${ }^{1}$ Amit Kumar, ${ }^{1}$ Vikash Nath, ${ }^{1}$ Parabita Basu, ${ }^{1}$ Amit Ojha, ${ }^{1}$ Andrew Copas, ${ }^{2}$ Tanja AJ Houweling, ${ }^{3}$ Hassan Haghparast-Bidgoli, ${ }^{2}$ Akay Minz, ${ }^{4}$ Pradeep Baskey, ${ }^{4}$ Manir Ahmed, ${ }^{4}$ Vasudha Chakravarthy, ${ }^{5}$ Riza Mahanta, ${ }^{5}$ Audrey Prost (iD ${ }^{2}$

To cite: Nair N, Tripathy PK, Gope R, et al. Effectiveness of participatory women's groups scaled up by the public health system to improve birth outcomes in Jharkhand, eastern India: a pragmatic cluster non-randomised controlled trial. BMJ Global Health 2021;6:e005066. doi:10.1136/ bmjgh-2021-005066

Handling editor Seye Abimbola

- Additional supplemental material is published online only. To view, please visit the journal online (http://dx.doi.org/10. 1136/bmjgh-2021-005066).

Received 15 July 2021 Accepted 8 0ctober 2021

Check for updates

(c) Author(s) (or their employer(s)) 2021. Re-use permitted under CC BY-NC. No commercial re-use. See rights and permissions. Published by BMJ.

For numbered affiliations see end of article.

Correspondence to Prof Audrey Prost; audrey.prost@ucl.ac.uk

\section{ABSTRACT}

Introduction The WHO recommends community mobilisation with women's groups practising participatory learning and action (PLA) to improve neonatal survival in high-mortality settings. This intervention has not been evaluated at scale with government frontline workers.

Methods We did a pragmatic cluster non-randomised controlled trial of women's groups practising PLA scaled up by government front-line workers in Jharkhand, eastern India. Groups prioritised maternal and newborn health problems, identified strategies to address them, implemented the strategies and evaluated progress. Intervention coverage and quality were tracked state-wide. Births and deaths to women of reproductive age were monitored in six of Jharkhand's 24 districts: three purposively allocated to an early intervention start (2017) and three to a delayed start (2019). We monitored vital events prospectively in 100 purposively selected units of 10000 population each, during baseline (1 March 2017-31 August 2017) and evaluation periods (1 September 2017-31 August 2019). The primary outcome was neonatal mortality. Results We identified 51949 deliveries and conducted interviews for 48589 (93.5\%). At baseline, neonatal mortality rates (NMR) were 36.9 per 1000 livebirths in the early arm and 39.2 in the delayed arm. Over 24 months of intervention, the NMR was 29.1 in the early arm and 39.2 in the delayed arm, corresponding to a $24 \%$ reduction in neonatal mortality (adjusted OR (AOR) 0.76, 95\% Cl 0.59 to 0.98 ), including 26\% among the most deprived (AOR $0.74,95 \% \mathrm{Cl} 0.57$ to 0.95 ). Twenty of Jharkhand's 24 districts achieved adequate meeting coverage and quality. In these 20 districts, the intervention saved an estimated 11803 newborn lives (min: 1026-max: 20 527) over 42 months, and cost 41 international dollars per life year saved.

Conclusion Participatory women's groups scaled up by the Indian public health system reduced neonatal mortality equitably in a largely rural state and were highly cost-effective, warranting scale-up in other high-mortality rural settings. Trial registration ISRCTN99422435.

\section{WHAT IS ALREADY KNOWN?}

$\Rightarrow$ An estimated 42 of 181 countries are off track to meet the Sustainable Development Goal targets for maternal and child survival by 2030 .

$\Rightarrow$ The WHO recommends community mobilisation through women's groups practising participatory learning and action (PLA) to improve neonatal survival in rural settings with low access to health services.

$\Rightarrow$ Little is known about whether this intervention can be scaled up with government frontline workers in high-mortality settings, and with what effect.

\section{WHAT ARE THE NEW FINDINGS?}

$\Rightarrow$ This large, pragmatic effectiveness trial found that government frontline workers and their supervisors could support participatory women's group meetings at scale in high-mortality districts of eastern India and reduced neonatal mortality by $24 \%$, with similar effects among the most deprived.

$\Rightarrow$ Effects on mortality were most likely driven by changes in thermal care practices, exclusive breastfeeding, and increased synergy with existing frontline worker activities, including postnatal visits.

$\Rightarrow$ Key systems enablers for scale-up included (1) government buy-in, driven by a view that participatory meetings with women's groups were an opportunity to build the capacities of frontline workers and support multiple health programmes at once; (2) health system innovations, including the rationalisation of frontline worker supervisors' catchment areas and workload, and the development of an on-the-job training system; (3) giving an enhanced role to frontline worker supervisors, who convened an estimated $60 \%$ of all group meetings. 


\section{WHAT DO THE NEW FINDINGS IMPLY?}

$\Rightarrow$ Women's groups practising PLA can reduce neonatal deaths when implemented by government frontline workers, at scale, in rural areas with high mortality.

$\Rightarrow$ This intervention could be further scaled up in high-mortality rural settings that need accelerated action to achieve the third Sustainable Development Goal target for neonatal mortality reduction.

\section{BACKGROUND}

Over 1 million women and 3.5 million newborn infants could be saved if the global Sustainable Development targets to reduce maternal and neonatal mortality were met by 2030. ${ }^{1}$ The WHO's Global Strategy for Women's, Children's and Adolescents' Health recommends two complementary community approaches to improve neonatal survival. ${ }^{2}$ The first is home visits to counsel families on birth preparedness and essential newborn care, and to treat or refer mothers and infants facing health problems. ${ }^{3}$ The second is community mobilisation through women's groups practising participatory learning and action (PLA). In this strategy, groups identify and prioritise health problems in the perinatal period, decide on strategies to address these, implement the strategies and evaluate progress. ${ }^{4}$ Systematic reviews have found that both community interventions with groups and home visits can reduce neonatal mortality, but have smaller effects at scale and as neonatal mortality declines. ${ }^{5-7}$

Accelerated action to improve birth outcomes would strongly benefit India, where $11 \%$ of all maternal deaths and $21 \%$ of neonatal deaths happen every year. ${ }^{89}$ Inequities in mortality remain high between and within Indian states: the eastern state of Bihar's neonatal mortality rate stands at 34.5 per 1000 livebirths, 10 times that of the southern state of Kerala (3.4). ${ }^{10}$ An estimated $44 \%$
$(315 / 720)$ of the country's districts need further action to reduce neonatal mortality to 12 per 1000 livebirths by $2030 .^{11}$ In 2016, building on two Indian efficacy trials, a multicountry meta-analysis and a WHO recommendation, India's National Health Mission advised 10 states to consider scaling up women's groups practising PLA. ${ }^{42-14}$ Little was known about whether this intervention could be scaled up with frontline workers embedded in the public health systems, and with what effects.

We report the results of a pragmatic cluster nonrandomised controlled trial (RCT) testing the effectiveness of participatory women's groups facilitated by government-incentivised frontline workers called Accredited Social Health Activists (ASHAs) and their supervisors on birth outcomes at scale in eastern India.

\section{METHODS}

\section{Study setting}

Jharkhand is a largely rural state of eastern India. Around a quarter $(26.2 \%)$ of the state's population belong to indigenous communities (Scheduled Tribes). ${ }^{15}$ Despite progress, the state's maternal mortality ratio and neonatal mortality rate remain high, at 76 per 100000 livebirths and 33 per 1000 livebirths, respectively. ${ }^{16} 17$

Figure 1 describes the study design. The National Health Mission of Jharkhand, the civil society organisation Ekjut and University College London were partners in evaluation. We used a non-randomised design because randomly allocating large geographical areas to ASHA training was unfeasible. We purposively selected six of Jharkhand's 24 districts for the evaluation and purposively allocated three to early intervention (May 2017) and the other three to delayed intervention (May 2019). Within the six evaluation districts, we purposively selected 20 blocks (subdistrict administrative units of $\mathrm{c}$.

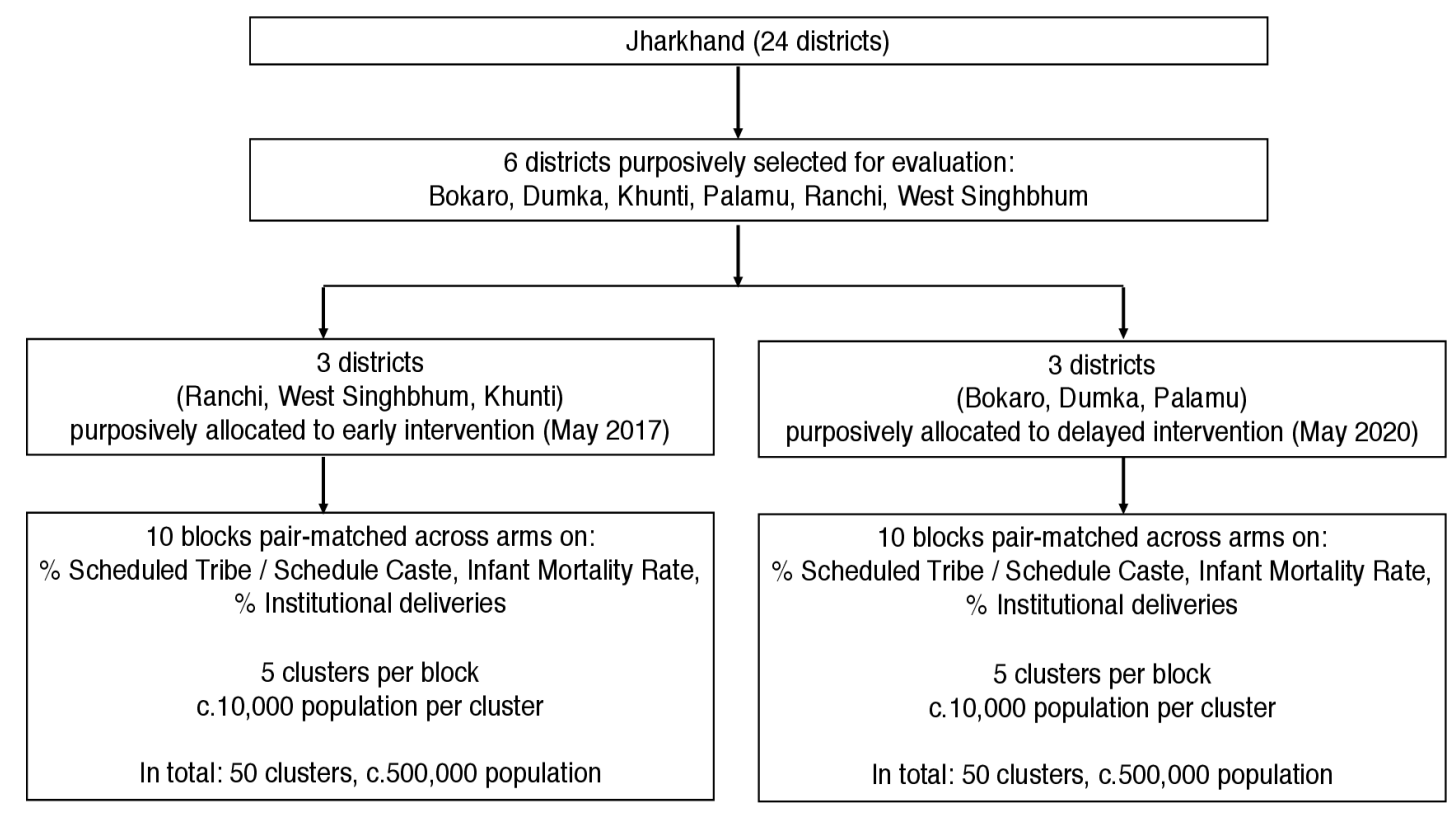

Figure 1 Study design. 
100000 population) for data collection by matching 10 blocks in the early arm to 10 blocks in the delayed arm. In each block, we selected five data collection units of c. 10 000 population each, or 100 units with a total population of 1038718 .

\section{Study participants}

Study participants were women of reproductive age (15-49 years) who gave birth between 1 March 2017 and 31 August 2019 in the 100 data collection units. We collected baseline data from 1 March 2017 to 31 August 2017, overlapping with the first 4 months of intervention. We assessed outcomes during a 2-year period (1 September 2017-31 August 2019). Women who declined to be interviewed and those who could not be found after at least three attempts within 120 days after delivery were excluded from analyses.

\section{Intervention}

The PLA cycle

The intervention was a cycle of monthly women's group meetings following principles of PLA. Meetings were usually held outdoors and were led by ASHAs and their supervisors-called ASHA facilitators-with approximately 1 ASHA facilitator for 15-20 ASHAs.

The PLA meeting cycle had four phases. In the first phase, ASHA facilitators and ASHAs encouraged groups to identify and prioritise maternal and newborn health problems using picture cards and voting. In the second phase, they created stories featuring the causes of problems prioritised by the group and potential solutions. Groups discussed these stories and solutions, then identified and prioritised locally feasible strategies to implement solutions in their communities. At the end of this second phase, groups organised a larger meeting in which they shared their prioritised problems with the wider community and sought support for the implementation of strategies. In the third phase, groups implemented their strategies and discussed other practical actions to improve maternal and newborn health (eg, preparing for emergencies during pregnancy). Meetings in the third phase were topic-based but used stories and games to enable dialogue about problems and solutions. In the fourth phase, groups evaluated the meeting cycle.

Changes to the intervention occurred during implementation. The cycle of meetings was originally planned for 30 months (1 May 2017-30 October 2019) and focused only on the perinatal period. In 2017, the National Health Systems Resource Centre (NHSRC) recommended incorporating issues covered in ASHAs' existing trainings and emerging findings from other studies into the PLA cycle. ${ }^{1819}$ As a result, additional meetings on infant and young child feeding, maternal nutrition, family planning, violence against women and other issues were added to the third phase of the cycle. This resulted in a total of 36 meetings, with roughly one meeting per month. Our 2-year evaluation period overlapped broadly with meetings $6-20$, that is, with meetings focused on perinatal health, maternal nutrition and childhood illnesses. The evaluation was costed for a predefined period of time; the expansion of the third phase during implementation meant that the third and fourth phases had not yet been fully completed by the time the evaluation ended. The full meeting cycle plan is in the online supplemental file. The manual is available online from India's NHSRC. ${ }^{20}$ In addition to facilitating PLA meetings, ASHAs also had a routine mandate to promote antenatal care and institutional deliveries, and to provide six postnatal home visits to newborn infants and mothers. ${ }^{21} 22$

\section{Training, supervision and incentives}

In 2017, Ekjut trained 645 master trainers, including state, district and block-level training team members. The training cascaded down from state to block levels until it reached ASHA facilitators. To support PLA, 1851 ASHA facilitators received three rounds of 5-day trainings on the first three phases of the cycle between 2017 and 2019, including 99\% (285/288) of all ASHA facilitators in the three early intervention districts.

A new training system was developed to support scale-up. Each ASHA facilitator gave the 20 villages in her catchment area an odd (eg, 1 or 3 ) or even (eg, 2 or 4) number. She led the first PLA meeting in all 10 'odd'-numbered villages in her catchment area, with ASHAs from nearby 'even'-numbered villages observing. These ASHAs returned to their even-numbered villages and facilitated PLA meetings. The following month, ASHA facilitators went to conduct meetings in villages with even numbers, and ASHAs from odd-numbered villages observed them. Using this approach, an ASHA facilitator led around 10 meetings per month and provided on-the-job training to all ASHAs in her catchment area over 2 months. Trainings were supplemented by monthly meetings with district-level coordinators and biannual meetings at a state level.

ASHA facilitators received an incentive of Indian Rupees (INR) 1000 (US\$13) to conduct 10 meetings a month, and ASHAs received INR 100 (US\$1.3) per meeting. They aimed to have around 1 group per 1000 population and encouraged pregnant women as well as women from Scheduled Tribes, Scheduled Castes and remote hamlets to participate.

The civil society organisation Ekjut supported government training teams, ASHA facilitators and ASHAs through 57 district-based PLA coordinators. These PLA coordinators were deployed in 6 out of 24 of Jharkhand's districts, including the 3 early intervention districts where the evaluation took place, and where there were a total of 26 PLA coordinators (approximately 1 PLA coordinator for c. 10000 population). PLA coordinators supported the mapping of ASHA facilitator working areas and helped organise trainings.

\section{Outcomes}

The trial's primary outcome was neonatal mortality. As per our analysis plan, we repeated the analysis for 
the primary outcome for the most deprived, defined as mothers belonging to the two poorest quintiles and who could not read or only with difficulty. Secondary outcomes included stillbirths, perinatal mortality, pregnancy-related deaths, as well as preventive and careseeking practices for women during the perinatal period. All outcomes were measured using a questionnaire survey administered through a prospective, community-based surveillance system described further below.

\section{Sample size, allocation and masking}

We initially calculated the sample size for the evaluation using blocks (district subunits) as the unit of allocation to early or delayed intervention. We expected around 2000 births in five data collection units per block over a 2-year evaluation period and estimated the baseline neonatal mortality rate in evaluation districts at 35 per 1000 livebirths. ${ }^{17}$ An evaluation with 10 blocks per arm would enable us to detect a $20 \%$ reduction in neonatal mortality with $80 \%$ power at the $95 \%$ significance level, using a coefficient of variation between clusters (k) of $0.1 .^{1423} \mathrm{In}$ 2016, the National Health Mission (Jharkhand) and Ekjut determined that allocating district subunits (blocks) to early or delayed intervention was not feasible, given all administrative and financial allocations from government as well as trainings were organised at a district level. This resulted in a change in allocation unit from blocks to district, leading to greater intervention feasibility but considerable loss of statistical power for the evaluation.

ASHAs facilitators and ASHAs could not be blinded to allocation. Data collection team members were blinded to allocation in theory, but could have noticed groups in their areas. Data analysts (HP, AP, TH and AC) were blind to allocation. Analysis for the primary outcome was conducted prior to unmasking.

\section{Data collection and management}

Ekjut evaluation team members were separate to those supporting the National Health Mission, Jharkhand. In each of the 100 data collection units, a network of five to six key informants (lay female community members) reported any births and deaths to women aged 15-49 years to a trained interviewer. Interviewers visited key informants on a monthly basis to collect a list of births and deaths, verified the reports' accuracy, paid informants INR 50 (US\$0.7) for each correct identification, and visited each home where a birth or death had been identified. ${ }^{24}$ One interviewer was responsible for a cluster of 10000 population. Interviews took place between 6 and 8 weeks after a birth or death. Interviewers used a structured questionnaire located on a smartphone application developed in CommCare. They asked mothers whether the infant was alive or had died and if so, when. Interviewers also used two questions about infant breathing and crying at birth to identify stillbirths. They then asked about events during pregnancy, delivery and the postnatal period. If a mother had died, interviewers asked her husband or other relatives about the timing of her death and events in the perinatal period. Supervisors aimed to observe around $20 \%$ of all interviews to provide feedback. The data manager (HP) downloaded data onto a secure server on a fortnightly basis to check completeness and accuracy using standardised Stata V.15 do files, then explored and addressed reasons for inconsistencies and missing data in fortnightly meetings with interviewers and supervisors. ${ }^{25}$ We did not carry out verbal autopsies to verify self-reported information on birth outcomes due to the large number of interviews conducted. We sought to minimise misclassification between stillbirths and neonatal deaths by labelling as undetermined all deaths recorded as stillbirths but for which the infant breathed or cried after birth, and those recorded as neonatal deaths but where the infant did not breathe or cry.

\section{Statistical analyses}

Analyses were by intention-to-treat, that is, based on all eligible mothers and infants, regardless of whether or not

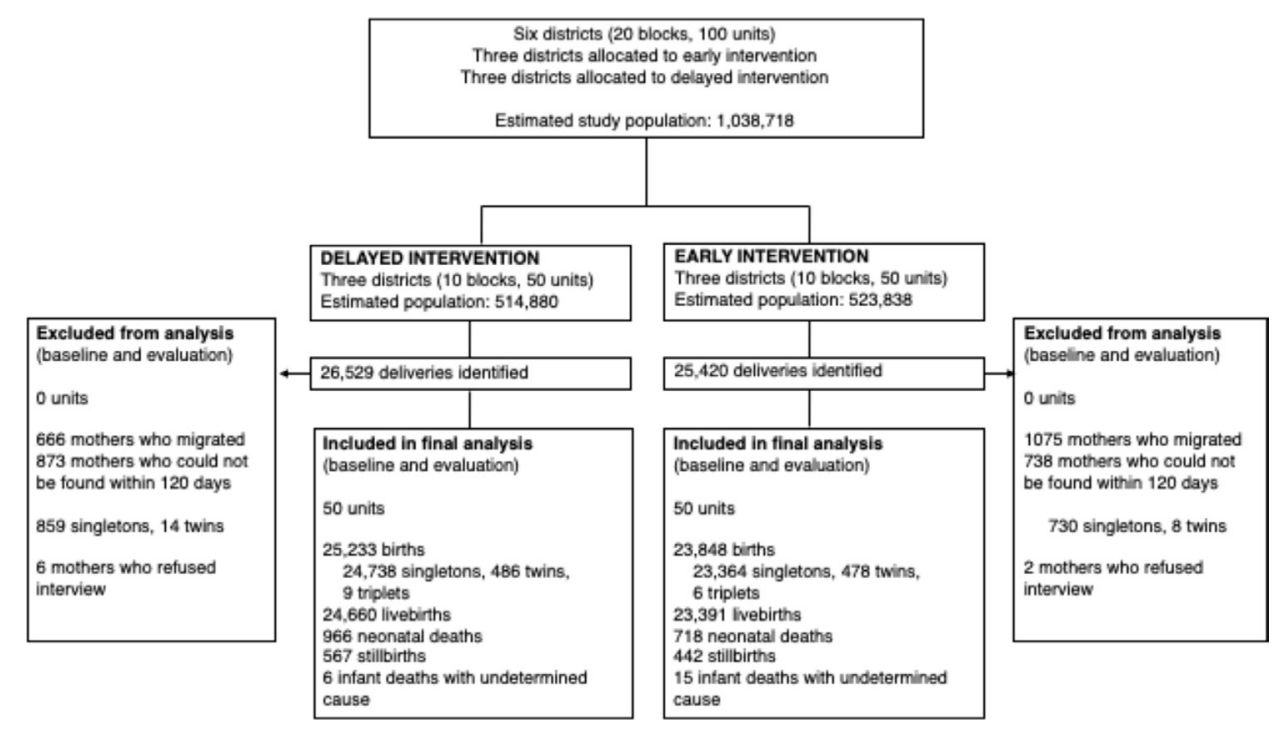

Figure 2 Trial profile. 
Table 1 Characteristics of mothers at baseline, by arm

\begin{tabular}{|llll}
\hline & Delayed arm & Early arm & All \\
\hline Mothers, $\mathrm{N}$ & 5370 & 4881 & 10251 \\
\hline District, $\mathrm{n}$ (\%) & & $1854(38.0)$ & - \\
\hline Ranchi & - & $1583(32.4)$ & - \\
\hline West Singhbhum & - & $1444(29.6)$ & - \\
\hline Khunti & - & - & - \\
\hline Bokaro & $832(15.5)$ & - & - \\
\hline Dumka & $2933(54.6)$ & - & - \\
\hline Palamu & $1605(29.9)$ & & \\
\hline Maternal age, mean (SD) & $24.6(8.1)$ & $25.4(7.1)$ & \\
\hline Caste/tribe distribution, $\mathrm{n}(\%)$ & & & \\
\hline Scheduled Tribe & $2632(49.0)$ & $2908(59.6)$ & $5540(54.1)$ \\
\hline Scheduled Class & $636(11.8)$ & $352(7.2)$ & $988(9.6)$ \\
\hline Other Backward Class & $1997(37.2)$ & $1573(32.2)$ & $3570(34.8)$ \\
\hline Other & $105(2.0)$ & $48(1.0)$ & $153(1.5)$ \\
\hline Asset wealth, $\mathrm{n}$ (\%) & & & \\
\hline First (poorest) wealth & $1221(22.7)$ & $860(17.6)$ & $2081(20.3)$ \\
\hline quintile & & & \\
\hline Second & $1207(22.5)$ & $834(17.1)$ & $2041(19.9)$ \\
\hline Third & $1188(22.1)$ & $845(17.3)$ & $2033(19.8)$ \\
\hline Fourth & $1035(19.3)$ & $1020(20.9)$ & $2055(20.1)$ \\
\hline Fifth (richest) wealth quintile & $719(13.4)$ & $1322(27.1)$ & $2041(19.9)$ \\
\hline Maternal literacy, $\mathrm{n}$ (\%) & & & \\
\hline Can read & $1941(36.1)$ & $2065(42.3)$ & $4006(39.1)$ \\
\hline Can read with difficulty & $1372(25.6)$ & $1048(21.5)$ & $2420(23.6)$ \\
\hline Cannot read & $2032(37.8)$ & $1752(35.9)$ & $3784(37.0)$ \\
\hline Maternal schooling, $\mathrm{n}$ (\%) & & & \\
\hline Has not attended school & $1559(29.0)$ & $1463(30.0)$ & $3022(29.5)$ \\
\hline Primary education & $1668(31.1)$ & $1079(22.1)$ & $2747(26.8)$ \\
\hline $\begin{array}{l}\text { Secondary education or } \\
\text { higher }\end{array}$ & $2118(39.4)$ & $2323(47.6)$ & $4441(43.3)$ \\
\hline Deprivation, $\mathrm{n}$ (\%) & & $3423(70.1)$ & $6857(66.9)$ \\
\hline Most deprived* & & & \\
\hline Less deprived & & & \\
\hline & & & \\
\hline
\end{tabular}

*Mothers who cannot read or can only read with difficulty and belong to the two poorest wealth quintiles.

they attended women's group meetings. We conducted a cluster-level analysis and treated districts as clusters. ${ }^{23}$ Our primary analysis was on adjusted cluster summary values. Adjusted values were derived by predicting the expected number of outcome events for each cluster in the absence of intervention and fitting a logistic regression model for the outcome based on four variables defined a priori (tribe/ caste, maternal schooling, maternal literacy and asset quintile). We did this separately for baseline and evaluation periods, for each cluster. The final analysis was an analysis of covariance (ANCOVA), that is, a regression of logit cluster summary values from the evaluation period adjusted for logit summary values at baseline, including allocation (early vs delayed) as a covariate. Counterintuitively, we observed that higher cluster baseline values were associated with lower cluster values during the evaluation period for some secondary outcomes. We therefore conducted an unplanned repeat analysis without adjustment for cluster-level baseline values but with the four a priori predictors of outcomes. All analyses were conducted in Stata V.15. ${ }^{25}$ The analysis for the primary outcome was prepared by an independent statistician (AC) who checked its results with masked intervention allocation.

\section{Process evaluation}

We carried out 12 semi-structured interviews with ASHA facilitators, ASHAs and government officials, five focus group discussions with community members, and collated information from 114 meeting observation sheets and 9 regional review meetings to understand key barriers and enablers to scale-up. We recorded the content of qualitative interviews, discussions and observations digitally or using written notes. We then coded transcripts and notes manually using the thematic analysis approach recommended by Braun and Clarke, with a focus on enablers and barriers to implementation and impacts within the health system and community. ${ }^{26}$ Full process evaluation results will be reported elsewhere. We used quality and coverage data collected by an agency independent from Ekjut and UCL using lot quality assurance sampling and the government's monitoring and information system to inform estimates of effects at scale, under assumptions described in the online supplemental file. ${ }^{27}$

\section{Economic evaluation}

We estimated the total cost and cost-effectiveness of the scaled-up intervention implemented in districts that met pre-specified coverage and quality benchmarks over 42 months (the full state-wide scale-up period), from a provider perspective. Data on costs were obtained from Ekjut and accounts of the National Health Mission, Jharkhand. Incremental cost-effectiveness ratios (ICERs) were estimated in terms of cost per neonatal death averted and cost per life-year saved. Life-years saved were estimated by multiplying the number of neonatal deaths averted by 30.8 , corresponding to a standard life expectancy of 86 years, discounted at $3 \%{ }^{28}$ All costs were adjusted for inflation, discounted at 3\% per year and converted to 2020 international dollars (INT\$) using the Purchasing Power Parity conversion factor of 21.2 for India.

\section{Registration}

We uploaded the data analysis plan to the ISRCTN registry prior to conducting the final analysis in March 2020.

\section{RESULTS}

Figure 2 is the trial profile. We identified 51949 deliveries during the baseline and evaluation periods, and conducted interviews following 48589 of these $(92.9 \%$ in the early intervention arm and $94.2 \%$ in the delayed arm).

Mothers in the early arm were more likely to be from a Scheduled Tribe, but also more likely to be literate and from the wealthiest asset quintile (table 1) due to districtlevel variations. At baseline, neonatal mortality rates were 36.9 per 1000 livebirths in the early arm and 39.2 in the delayed arm. 
Table 2 Births, deaths and crude mortality rates by arm

\begin{tabular}{|c|c|c|c|c|c|c|}
\hline & Baseline peri & & & Evaluation pe & eriod & \\
\hline & Delayed arm & Early arm & All & Delayed arm & Early arm & All \\
\hline Births & 5421 & 4922 & 10343 & 19812 & 18926 & 38738 \\
\hline Livebirths & 5278 & 4826 & 10104 & 19382 & 18565 & 37947 \\
\hline Stillbirths & 142 & 88 & 230 & 425 & 354 & 779 \\
\hline Neonatal deaths ( $0-28$ days) & 207 & 178 & 385 & 759 & 540 & 1299 \\
\hline Early neonatal deaths ( $0-6$ days) & 164 & 134 & 298 & 612 & 387 & 999 \\
\hline Late neonatal deaths (7-28 days), $\mathrm{N}$ & 43 & 44 & 87 & 147 & 153 & 300 \\
\hline Perinatal deaths & 306 & 222 & 528 & 1037 & 741 & 1778 \\
\hline Infants with undetermined outcomes* & 1 & 8 & 9 & 5 & 7 & 12 \\
\hline Pregnancy-related deaths & 19 & 12 & 31 & 62 & 50 & 112 \\
\hline Neonatal mortality rate per 1000 live births & 39.2 & 36.9 & 38.1 & 39.2 & 29.1 & 34.2 \\
\hline Early neonatal mortality rate per 1000 live births & 31.1 & 27.8 & 29.5 & 31.6 & 20.8 & 26.3 \\
\hline Late neonatal mortality rate per 1000 live births & 8.1 & 9.1 & 8.6 & 7.6 & 8.2 & 7.9 \\
\hline Stillbirth rate per 1000 births & 26.2 & 17.9 & 22.2 & 21.4 & 18.7 & 20.1 \\
\hline Perinatal mortality rate per 1000 births & 56.4 & 45.1 & 51.0 & 52.3 & 39.1 & 45.9 \\
\hline Pregnancy-related mortality ratio per 100000 live births & 360.0 & 248.6 & 306.8 & 319.9 & 269.3 & 295.1 \\
\hline
\end{tabular}

*These deaths were either: (1) recorded as stillbirths but with the infant breathing or crying after birth; or (2) recorded as neonatal deaths but with no breathing or crying. We sought to minimise the risk of misclassification by reporting these infants as having an undetermined outcome and conducted sensitivity analyses to examine the effect of classifying them as either stillbirths or neonatal deaths.

During the 24-month evaluation period, the neonatal mortality rate was 29.1 per 1000 live births in the early arm and 39.2 in the delayed arm (table 2). This corresponded to a $24 \%$ reduction in neonatal mortality (adjusted OR (AOR) 0.76, 95\% CI 0.59 to 0.98) (table 3). Neonatal mortality was reduced by $26 \%$ among the most deprived (AOR 0.74, 95\% 0.57-0.95). Full results for the most deprived are in the online supplemental file.

Figure 3 describes changes in neonatal mortality in early and delayed intervention arms by season. Neonatal mortality reductions were more pronounced in the early intervention arm during winter and summer. We found no evidence of effects on stillbirths (AOR 1.57, 95\% CI 0.96 to 2.58 ), perinatal mortality (AOR $0.87,95 \%$ CI 0.73 to 1.04 ) or pregnancy-related mortality (AOR 1.06, 95\% CI 0.81 to 1.41) (table 3).

Table 4 describes preventive and care-seeking practices for mothers and newborn infants. Effects were consistently in the hypothesised direction across all models for 10 of 16 secondary outcomes. The fully adjusted models (model 3) suggest that the intervention increased early infant wiping (model 3 AOR 1.64, 95\% CI 1.05 to 2.58), exclusive breastfeeding (model 3 AOR 22.7, 95\% CI 4.95 to 104) and postnatal ASHA visits (model 3 AOR 1.27, 95\% CI 1.07 to 1.50). The intervention may have increased infant wrapping (model 3 AOR 1.92, 95\% CI 0.51 to 7.22) and the proportion of mothers receiving three antenatal care check-ups (model 3 AOR 4.68, 95\% CI 0.90 to 24.3), but CIs were

Table 3 Effects on birth outcomes (cluster-level analyses) ${ }^{\star}$

\begin{tabular}{|c|c|c|}
\hline & $\begin{array}{l}\text { Minimally adjusted model } \\
\text { OR }(95 \% \mathrm{Cl}) \dagger\end{array}$ & $\begin{array}{l}\text { Fully adjusted model } \\
\text { OR }(95 \% \mathrm{Cl}) \ddagger\end{array}$ \\
\hline Neonatal mortality rate per 1000 live births & $0.75(0.55$ to 1.00$)$ & $0.76(0.59$ to 0.98$)$ \\
\hline Late neonatal mortality rate per 1000 live births & $0.93(0.72$ to 1.20$)$ & $0.96(0.62$ to 1.50$)$ \\
\hline Perinatal mortality rate per 1000 births & $0.87(0.65$ to 1.16$)$ & $0.87(0.73$ to 1.04$)$ \\
\hline Pregnancy-related mortality ratio per 100000 livebirths $\S$ & $1.05(0.45$ to 2.46$)$ & $1.06(0.81$ to 1.41$)$ \\
\hline
\end{tabular}

${ }^{*}$ Clusters are districts.

†Adjusted for baseline differences in the outcome only.

†Adjusted for baseline values, tribal/caste status, maternal education, maternal literacy and household asset quintile.

$\S$ Adjusted for tribal/caste status and household asset quintile only, as outcome did not vary by maternal education or maternal literacy. 


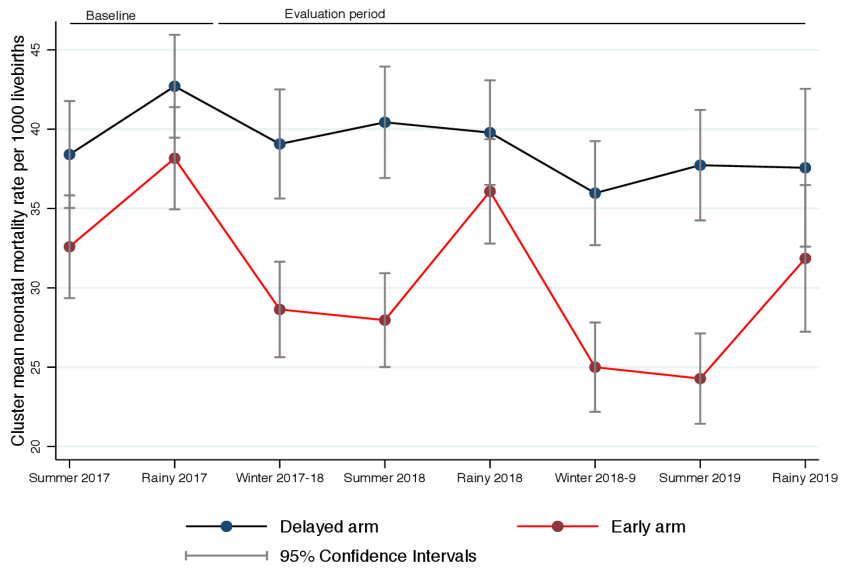

Figure 3 Neonatal mortality rates in early and delayed intervention arms, by season.

wide and included one. We found no effects on institutional delivery (model 3 AOR $1.26,95 \%$ CI 0.78 to 2.05), skilled birth attendance (model 3 AOR 1.24, 95\% CI 0.75 to 2.04) or care-seeking for a health problem for mothers (model 3 AOR 1.07, 95\% CI 0.50 to 2.29) and newborn infants (model 3 AOR $0.62,95 \%$ CI 0.21 to 1.84 ).

\section{Scale-up coverage, enablers and barriers}

The median number of women's group participants in the three early intervention districts over the 2-year evaluation period was 20 (IQR 17-25). Over the 2-year evaluation period, $46 \%(8644 / 18683)$ of mothers interviewed in the three early intervention districts said they had ever attended a PLA meeting, as did 40.6\% (2175/5363) of the most deprived mothers (data not shown).

Jharkhand has 24 districts, 21 of which started the intervention between 2016 and 2017. Independent observations of 1594 meetings by a third party agency found that 20 of those 21 districts had $30 \%$ or more of pregnant women in ASHA catchment areas participating. The government's monitoring data showed that two-thirds or more of groups across these 20 districts completed all perinatal meetings (online supplemental file). Box 1 summarises health systems enablers and barriers to scale-up.

\section{Estimated number of newborn lives saved at scale}

In early intervention areas (population: 523 838), we estimated that the intervention saved 188 neonatal lives over 2 years (min: 16-max: 327). The scale-up occurred in three phases, starting with six blocks in 2015-2016 and gradually expanding to 21 districts from 2017 onwards. The three delayed evaluation districts received the intervention in 2019. A priori, we proposed that the effect on neonatal mortality observed in the three early intervention districts could be extrapolated to other districts in the state if (1) training teams and ASHA facilitators in these districts had received all PLA trainings, (2) twothirds or more of groups had completed perinatal meetings (meetings 1-16) and (3) $30 \%$ or more of pregnant women in ASHA catchment areas had ever participated in groups. These criteria were met in 20 of Jharkhand's 24 districts. We estimated that the intervention saved 11803 neonatal lives in these 20 districts (min: 1026max: 20 527) during the scale-up. Data and justification for assumptions are in online supplemental file 1.

\section{Costs and cost-effectiveness}

The total and annual programme implementation costs in 20 districts were INR 318488929 (INT\$15 017 396) and INR 94018573 (INT\$4 433 165), respectively. Cost per person covered and per livebirths were INT $\$ 0.6$ and INT \$9.4, respectively. ICERs were INT $\$ 1272$ (range: INT \$732-INT\$14 632) per neonatal death averted or INT\$41 (range: INT\$24-INT\$475) per life year saved. The full economic evaluation will be reported elsewhere.

\section{DISCUSSION}

Participatory women's groups embedded within India's public health system improved neonatal survival at scale, with equitable benefits for the most deprived, and were costeffective. To our knowledge, this study is the largest pragmatic trial of a community mobilisation intervention with groups to improve birth outcomes. The intervention's effect on neonatal mortality was similar to that found in earlier efficacy RCTs of community interventions with groups (Risk Ratio [RR] $0.83,95 \%$ CI 0.74 to 0.92$).^{5}$ It was also larger than the effect found in the four existing effectiveness trials of demand-focused community interventions to improve maternal and newborn health, ${ }^{29-32}$ with one exception. ${ }^{29}$ In India, no other group-led interventions have demonstrated benefits for neonatal survival on a large scale. A smaller RCT $(<15000$ births $)$ of a health education intervention delivered by ASHAs to mothers' groups in Uttar Pradesh found improvements in perinatal preventive and care-seeking behaviours, but not neonatal survival. ${ }^{33}$ Several quasiexperimental studies with under 5000 participants each have also tested the effects of 'layering' health education onto women's self-help groups in Uttar Pradesh and Bihar. ${ }^{34-37}$ They found increases in women's knowledge of perinatal danger signs and selected practices, but all reported effects on group members only rather than at a population level, and none measured birth outcomes.

What were the most plausible mechanisms for neonatal mortality reduction in this study? Strategies employed by groups were informed by local contexts and assets. Early infant wiping and exclusive breastfeeding were largely under the control of women and their families and appear to have increased due to the intervention. Improvements in essential newborn care practices and winter gains in neonatal survival are consistent with those documented in at least four earlier South Asian randomised trials of this intervention. ${ }^{38}$ Increases in preventive practices may have played a role in helping small infants in a context where over twothirds of neonatal deaths are linked to prematurity and low birth weight. ${ }^{9}$ Group members may also have capitalised on the presence of ASHAs to help them access antenatal care, though we found no reductions in stillbirths, perhaps due to 


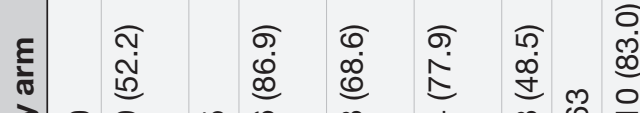

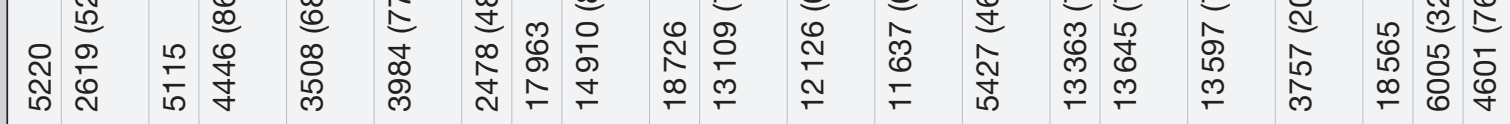

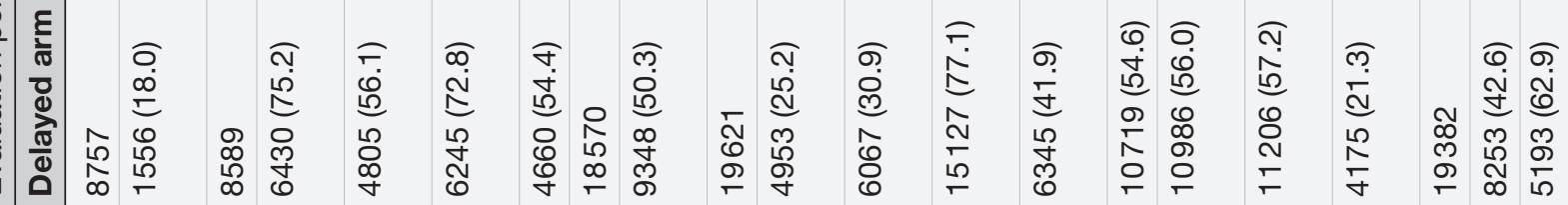

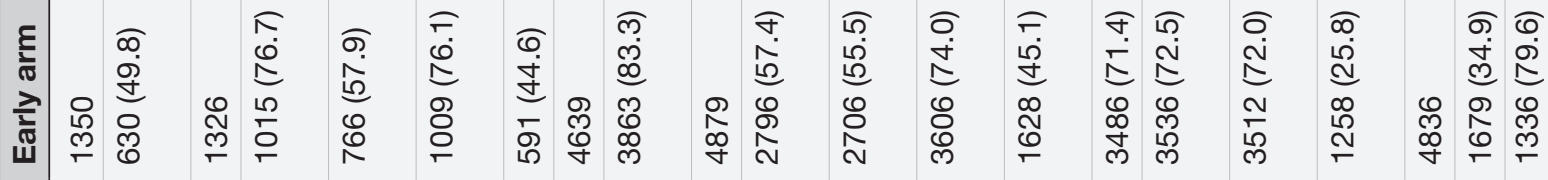
مิ<smiles>C1CCCC1</smiles>

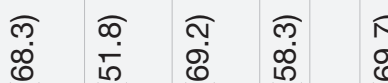
ז̊

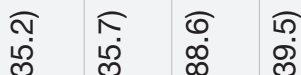
ธุด ชุ สุ 0 勇

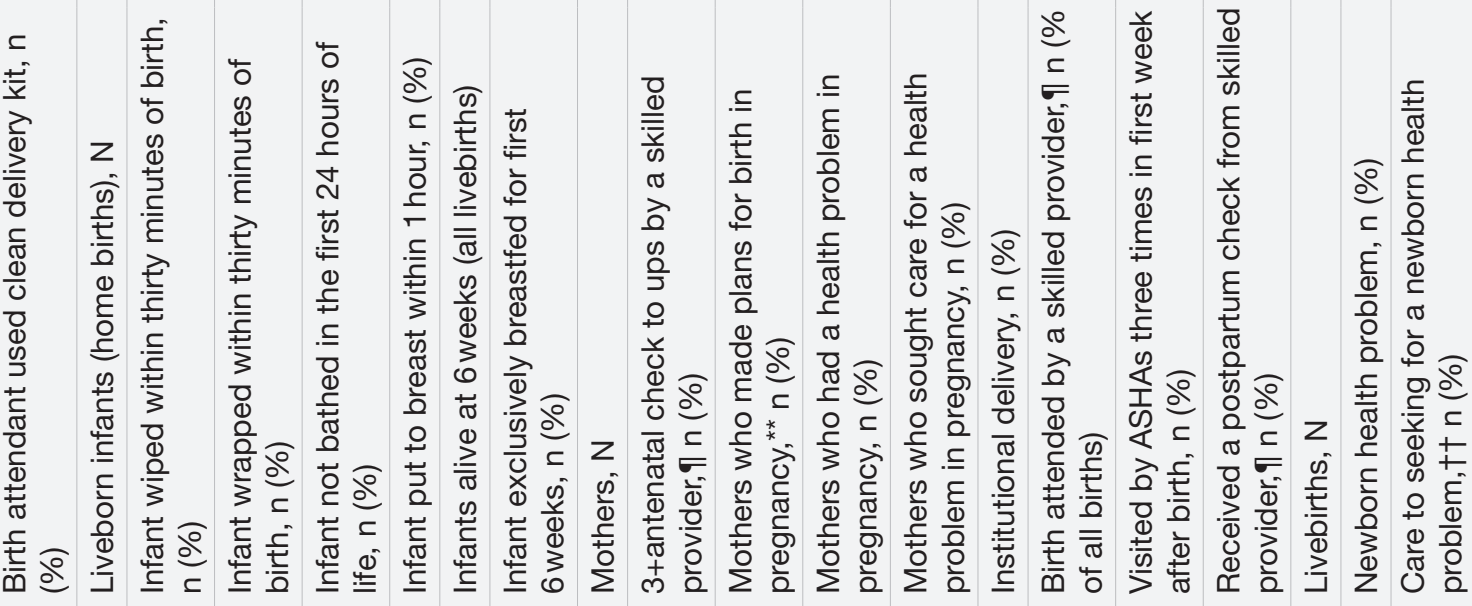


Box 1 Enablers and barriers to scale-up: a health systems perspective

Early process evaluation interviews with functionaries of the National Health Mission, Jharkhand, as well as 12 ASHAs and ASHA facilitators highlighted several systems-level enablers for scale-up: (1) government buy in, driven by a view that participatory meetings with women's groups were an opportunity to build the capacities of frontline community health workers and support multiple health programmes at once; (2) health systems innovations, including the rationalisation of ASHA facilitators' catchment areas and workload, and the development of an on-the-job training system; and (3) giving an enhanced role to ASHA facilitators, who convened an estimated $60 \%$ of all group meetings. Key systems-level barriers to scale-up included (1) ASHA vacancies due to dropouts and replacements; (2) delays in printing training modules; (3) ASHAs being involved in multiple tasks, some of them unplanned engagements given at short notice (eg, immunisation drives); (4) lack of support from ASHAs' family members; and (5) distance between meeting locations. Despite these barriers, both ASHA facilitators and ASHAs said they were motivated by incentives for the meetings, the satisfaction of being useful to the community and respected, as well as acquiring new skills and knowledge. ASHA, Accredited Social Health ctivists.

gaps in the quality of care in health facilities. ${ }^{39}$ Malaria and anaemia in pregnancy were both also likely contributors to continuing high rates of stillbirths, prematurity and low birth weight in the study areas. ${ }^{40}$

Why was neonatal mortality reduction equitable, that is, of similar magnitude among less and most deprived families? Due to higher baseline mortality, the similar proportional mortality reduction among deprived families corresponded to a larger absolute mortality reduction in this group. An earlier meta-analysis of efficacy trials of this intervention in Nepal, Bangladesh, Malawi and India found a similar effect. ${ }^{41}$ Like facilitators in earlier trials, ASHAs and ASHA facilitators were from the communities they served, joining PLA meetings did not require being literate or contributing money, and ASHAs strived to include the most concerned and at risk: pregnant women and those from underserved communities. ${ }^{42}$

The intervention was highly cost-effective by WHO and other gross domestic product-based cost-effectiveness thresholds. ${ }^{43} 44$ The ICERs estimated in this study were substantially lower than those reported in earlier efficacy trials of participatory women's groups in India. ${ }^{45}$ Employing incentivised ASHAs and ASHA facilitators as well as building these frontline workers' capacity through on-the-job-training reduced costs at scale. The intervention covered 1.6 million live births at a cost of INT $\$ 9.4$ per live birth compared with average cost per live birth of INT \$203 (range: 2016 INT \$61-INT\$537) in efficacy trials. ${ }^{46}$

Our study benefited from a large sample size, low attrition levels and conservative statistical methods. It also had limitations. The lack of randomisation and purposive selection of study areas may have led to selection 
and confounding bias not fully addressed through statistical adjustment. The loss of statistical power caused by using districts as allocation units made it nearly impossible to detect changes in secondary outcomes. We also had some non-intuitive findings for several secondary outcomes as we adjusted for baseline values with a modest number of clusters. Our estimates of newborn lives saved at scale rely on the accuracy of data from the government monitoring and information system and a third-party evaluation. They also rely on the comparability between evaluation districts and other districts in the state. In addition, we assumed that the intervention delivered in the three 'early arm' districts was broadly similar and not more intensive to that delivered in other scale-up districts. Although the presence of Ekjut PLA coordinators in the early intervention districts was important, their coverage -at one per 10000 populationwas not deemed intense, and lessons from these districts were replicated in the state-wide scale-up. Finally, we have presented only a brief summary of health systems enablers and barriers to scale-up. Making participation a norm within the context of a government scale-up is inherently challenging. ${ }^{47}$ As pointed out by Abimbola, further scale-up of community engagement interventions should not 'simply' be determined by whether they improve health outcomes but also by an understanding of why, how and under what circumstances engagement occurs. ${ }^{48}$ Trials are only one part of a more complete and cumulative programme of work to discover "why things work' rather than 'what works'. ${ }^{49}$ To understand why this scale-up may have worked and what could be improved, we will therefore conduct a mixed-methods process evaluation exploring the intervention's implementation and mechanisms in context.

Is community mobilisation with participatory women's groups still relevant in the context of increased access to health facilities? Our study took place in districts where neonatal mortality rates remained high at baseline (>33), despite over half of women giving birth in health facilities and the gradual scale-up of newborn stabilisation units and special newborn care units. ${ }^{50}$ Our findings support WHO's 2014 recommendation to support participatory women's groups where neonatal mortality remains high. ${ }^{4}$ Our results are also directly relevant to the 315 Indian districts that need accelerated action to achieve the third Sustainable Development Goal target for neonatal survival, of which 231 had an NMR of $\geq 33$ in 2005-2015. ${ }^{11}$ As neonatal survival improves, community mobilisation interventions with groups will have more limited impact on mortality and should shift their focus towards improving linkages between communities and health facilities, strengthening accountability for quality facility-based care, and tackling other health and wellbeing issues relevant to group members. ${ }^{51}{ }^{52}$ Groups are not simply a 'platform' to deliver health messages; when engaged using dialogue-based, participatory methods, they can be an engine to support community engagement for universal health coverage. ${ }^{53-55}$

\section{CONCLUSION}

Participatory women's groups scaled up by the public health system improved neonatal survival equitably in a largely rural state of India and were highly cost-effective. The intervention could be further scaled up in highmortality rural areas of India and other countries.

\section{Author affiliations}

${ }^{1}$ Ekjut, Chakradharpur, India

${ }^{2}$ Institute for Global Health, University College London, London, UK

${ }^{3}$ Department of Public Health, Erasmus MC, University Medical Centre Rotterdam,

Rotterdam, The Netherlands

${ }^{4}$ Jharkhand State Health Mission, Ranchi, India

${ }^{5}$ Development Solutions, New Delhi, India

Twitter Audrey Prost @audreyprost2

Acknowledgements We thank women's group members, mothers and their family members who gave their time to be interviewed and all members of the partnering communities. We thank the Accredited Social Health Activists (ASHA) facilitators and ASHAs of Jharkhand, who led the intervention. We thank Dr Suranjeen Pallipamula, Professor Joanna Schellenberg and Dr Rajani Ved for acting as members of the advisory group for this study. We are grateful to the National Health System Resource Centre and Community Mobilisation Cell of National Health Mission, Jharkhand, for their inputs. We also thank Vishal Chandra, Smita Todkar, Prabas Kumar Sahoo, Sarfraz Ali, Sanjay Kumar, Enem Aind, Vijay Singh, Nirakar Panda, Sumitra Gagrai, Nibha Das, all district managers and training team members including Priyanka Banerjee, Vikas Kumar, Nawab Parvez, Jyoti Mundri, Poonam Devi and Ravi Das for support in the field. We thank the state and block training teams of the National Health Mission, Jharkhand, for supporting the intervention and study. We thank Erin McCarthy, Manjula Singh, Hemang Shah and Mihretab Salasibew for supporting the evaluation at the Children's Investment Fund Foundation.

Contributors AP conceptualised the study and developed its methods with HP NN, ShR, SuR, PKT, VN, RG, and AK. HP, AP, TH and AC carried out the analyses. ShR and HP led the quantitative data collection and cleaning. SuR led the analysis of the qualitative data. VC and RM collected and analysed data for the third-party evaluation by Development Solutions used to estimate effects of the intervention at scale. PBasu analysed data from the Monitoring and Information System. A0 and $\mathrm{HH}-\mathrm{B}$ led the collation and analysis of cost data. AP wrote the first draft of the article and collated subsequent inputs. All authors, including AM, PBask and MA, commented on drafts of the manuscript. AP acquired the funding and oversaw the grant that funded the study. AP, HP and TH had access to all underlying data. AP acts as guarantor.

Funding The study was funded by the Children's Investment Fund Foundation (grant number G160100937). The funder had no role in designing the study, data collection and analysis, the decision to publish or the preparation of this manuscript.

Competing interests AM, PBask and MA are employed by Jharkhand's State Health Mission. Other authors declare that they have no conflicts of interest.

Patient consent for publication Not applicable.

Ethics approval The study was approved by an independent ethics research committee linked to Ekjut in Ranchi on 19 August 2016 and by University College London's Research Ethics Committee (reference: 1881/003). We sought individual informed consent from all individual participants and recorded it through signature or thumbprint.

Provenance and peer review Not commissioned; externally peer reviewed.

Data availability statement All data relevant to the study are included in the article or uploaded as supplementary information. De-identified participant data and a STATA do file to replicate analyses are included as supplementary files with our publication.

Supplemental material This content has been supplied by the author(s). It has not been vetted by BMJ Publishing Group Limited (BMJ) and may not have been peer-reviewed. Any opinions or recommendations discussed are solely those of the author(s) and are not endorsed by BMJ. BMJ disclaims all liability and responsibility arising from any reliance placed on the content. Where the content includes any translated material, BMJ does not warrant the accuracy and reliability 
of the translations (including but not limited to local regulations, clinical guidelines, terminology, drug names and drug dosages), and is not responsible for any error and/or omissions arising from translation and adaptation or otherwise.

Open access This is an open access article distributed in accordance with the Creative Commons Attribution Non Commercial (CC BY-NC 4.0) license, which permits others to distribute, remix, adapt, build upon this work non-commercially, and license their derivative works on different terms, provided the original work is properly cited, appropriate credit is given, any changes made indicated, and the use is non-commercial. See: http://creativecommons.org/licenses/by-nc/4.0/.

ORCID iD

Audrey Prost http://orcid.org/0000-0001-6121-8132

\section{REFERENCES}

1 McArthur JW, Rasmussen K, Yamey G. How many lives are at stake? assessing 2030 sustainable development goal trajectories for maternal and child health. BMJ 2018;360:k373.

2 World Health Organization. Global strategy for women's, children's and adolescents' health (2016-2030), 2021. Available: http://www. who.int/life-course/partners/global-strategy/en/

3 World Health Organization. WHO recommendations: postnatal care of mother and newborn. Geneva: World Health Organization, 2013.

4 World Health Organization. WHO recommendation on community mobilization through facilitated participatory learning and action cycles with women's groups for maternal and newborn health. Geneva: World Health Organization, 2014.

5 Lassi ZS, Kedzior SG, Bhutta ZA. Community-Based maternal and newborn educational care packages for improving neonatal health and survival in low- and middle-income countries. Cochrane Database Syst Rev 2019;2019:CD007647.

6 Kirkwood BR, Manu A, ten Asbroek AHA, et al. Effect of the Newhints home-visits intervention on neonatal mortality rate and care practices in Ghana: a cluster randomised controlled trial. Lancet 2013;381:2184-92.

7 Hanson C, Kujala S, Waiswa P, et al. Community-Based approaches for neonatal survival: meta-analyses of randomized trial data. Bull World Health Organ 2017:95:453-64.

8 WHO, UNICEF, UNFPA, World Bank Group, and the United Nations Population Division. Trends in maternal mortality: 2000 to 2017. Geneva: World Health Organization, 2019.

9 UN Inter-Agency Group for Child Mortality Estimation. Levels and trends in child mortality: report 2020. New York: United Nations Children's Fund; World Health Organization; The World Bank; United Nations, Department of Economic and Social Affairs, Population Division; United Nations Economic Commission for Latin America and the Caribbean, Population Division, 2020.

10 IIPS, ICF. National family health survey (NFHS-5), 2019-20, phase I: India. Mumbai: International Institute for Population Sciences, 2020.

11 Bora JK, Saikia N. Neonatal and under-five mortality rate in Indian districts with reference to sustainable development goal 3: an analysis of the National family health survey of India (NFHS), 2015 2016. PLoS One 2018;13:e0201125.

12 Tripathy P, Nair N, Barnett S, et al. Effect of a participatory intervention with women's groups on birth outcomes and maternal depression in Jharkhand and Orissa, India: a cluster-randomised controlled trial. Lancet 2010;375:1182-92.

13 Tripathy P, Nair N, Sinha R, et al. Effect of participatory women's groups facilitated by accredited social health activists on birth outcomes in rural eastern India: a cluster-randomised controlled trial. Lancet Glob Health 2016;4:e119-28.

14 Prost A, Colbourn T, Seward N, et al. Women's groups practising participatory learning and action to improve maternal and newborn health in low-resource settings: a systematic review and metaanalysis. Lancet 2013;381:1736-46.

15 Office of the Registrar General \& Census Commissioner. Census of India. New Delhi, 2011. Available: https://censusindia.gov.in/ 2011census/censusinfodashboard/stock/profiles/en/IND020 Jharkhand.pdf

16 Ministry of Home Affairs, Government of India. Special Bulletin on maternal mortality in India 2015-2017. New Delhi: Office of the Registrar General \& Census Commissioner, 2019. https:// censusindia.gov.in/vital_statistics/SRS Bulletins/MMR_Bulletin2015-17.pdf

17 IIPS, ICF. National family health survey (NFHS-4), 2015-16: India Mumbai: International Institute for Population Sciences, 2017.

18 Nair N, Tripathy P, Sachdev HPS. Effect of participatory women's groups and counselling through home visits on children's linear growth. Lancet Global Health 2016;5:PE1004-16.
19 Nair N, Daruwalla N, Osrin D, et al. Community mobilisation to prevent violence against women and girls in eastern India through participatory learning and action with women's groups facilitated by accredited social health activists: a before-and-after pilot study. BMC Int Health Hum Rights 2020;20:6

20 National Health Mission. Participatory learning and action module for ASHA Facilitator/ASHA, 2017.New Delhi. Available: https:// nhsrcindia.org/sites/default/files/2021-06/PLA\%20Module\%20for\% 20ASHA_English.pdf

21 Government of India Ministry of Health and Family Welfare. HomeBased newborn care: operational guidelines. New Delhi: Government of India Ministry of Health and Family Welfare, 2014.

22 Scott K, George AS, Ved RR. Taking stock of 10 years of published research on the ASHA programme: examining India's national community health worker programme from a health systems perspective. Health Res Policy Sys 2019;17:29.

23 Hayes RJ, Moulton LH. Cluster randomised trials. 2nd Edition. London: CRC Press, 2017

24 Barnett S, Nair N, Tripathy P, et al. A prospective key informant surveillance system to measure maternal mortality - findings from indigenous populations in Jharkhand and Orissa, India. BMC Pregnancy Childbirth 2008;8:6.

25 StataCorp. Stata statistical software: release 15. College Station, TX: StataCorp LLC, 2015.

26 Braun V, Clarke V. Using thematic analysis in psychology. Qual Res Psychol 2006;3:77-101.

27 Robertson SE, Valadez JJ. Global review of health care surveys using lot quality assurance sampling (LQAS), 1984-2004. Soc Sci Med 2006;63:1648-60.

28 World Health Organization. WHO methods and data sources for global burden of disease estimates 2000-2015. Global health estimates technical paper. Geneva: Department of Information, Evidence and Research, World Health Organization, 2017.

29 Bhutta ZA, Soofi S, Cousens S, et al. Improvement of perinatal and newborn care in rural Pakistan through community-based strategies: a cluster-randomised effectiveness trial. Lancet 2011;377:403-12.

30 Bhandari N, Mazumder S, Taneja S, et al. Effect of implementation of integrated management of neonatal and childhood illness (IMNCI) programme on neonatal and infant mortality: cluster randomised controlled trial. BMJ 2012;344:e1634

31 Degefie Hailegebriel T, Mulligan B, Cousens S. Effect on neonatal mortality of newborn infection management at health posts when referral is not possible: a cluster-randomized trial in rural Ethiopia Global Health: Science and Practice 2017:5:202-16.

32 Morrison J, Tumbahangphe K, Sen A, et al. Health management Committee strengthening and community mobilisation through women's groups to improve trained health worker attendance at birth in rural Nepal: a cluster randomised controlled trial. BMC Pregnancy Childbirth 2020;20:268.

33 Acharya A, Lalwani T, Dutta R, et al. Evaluating a large-scale community-based intervention to improve pregnancy and newborn health among the rural poor in India. Am J Public Health 2015;105:144-52.

34 Saggurti N, Atmavilas Y, Porwal A, et al. Effect of health intervention integration within women's self-help groups on collectivization and healthy practices around reproductive, maternal, neonatal and child health in rural India. PLoS One 2018;13:e0202562.

35 Mozumdar A, Khan ME, Mondal SK, et al. Increasing knowledge of home based maternal and newborn care using self-help groups: evidence from rural Uttar Pradesh, India. Sex Reprod Healthc 2018;18:1-9.

36 Saggurti N, Porwal A, Atmavilas Y, et al. Effect of behavioral change intervention around new-born care practices among most marginalized women in self-help groups in rural India: analyses of three crosssectional surveys between 2013 and 2016. J Perinatol 2019;39:990-9.

37 Hazra A, Maternal AJ. newborn and child health behaviors in rural uttar pradesh: findings from learning phase endline survey, 2015. New Delhi: Population Council, 2016.

38 Seward N, Neuman M, Colbourn T, et al. Effects of women's groups practising participatory learning and action on preventive and careseeking behaviours to reduce neonatal mortality: a meta-analysis of cluster-randomised trials. PLoS Med 2017;14:e1002467.

39 Tripathi S, Srivastava A, Memon P, et al. Quality of maternity care provided by private sector healthcare facilities in three states of India: a situational analysis. BMC Health Serv Res 2019;19:971.

40 Kumari S, Garg N, Kumar A, et al. Maternal and severe anaemia in delivering women is associated with risk of preterm and low birth weight: a cross sectional study from Jharkhand, India. One Health 2019;8:100098.

41 Houweling TAJ, Looman CWN, Azad K, et al. The equity impact of community women's groups to reduce neonatal mortality: a 
meta-analysis of four cluster randomized trials. Int J Epidemiol 2019;48:168-82

42 Morrison J, Osrin D, Alcock G, et al. Exploring the equity impact of a maternal and newborn health intervention: a qualitative study of participatory women's groups in rural South Asia and Africa. Int $J$ Equity Health 2019;18:55.

43 Tan-Torres Edejer TBR, Adam T, Hutubessy R. Making choices in health: WHO guide to cost-effectiveness analysis. Geneva: World Health Organization, 2003.

44 Woods B, Revill P, Sculpher M, et al. Country-Level costeffectiveness thresholds: initial estimates and the need for further research. Value Health 2016;19:929-35.

45 Sinha RK, Haghparast-Bidgoli H, Tripathy PK, et al. Economic evaluation of participatory learning and action with women's groups facilitated by accredited social health activists to improve birth outcomes in rural eastern India. Cost Eff Resour Alloc 2017;15:2.

46 Pulkki-Brännström A-M, Haghparast-Bidgoli $\mathrm{H}$, Batura N, et al. Participatory learning and action cycles with women's groups to prevent neonatal death in low-resource settings: a multi-country comparison of cost-effectiveness and affordability. Health Policy Plan 2021;35:1280-9.

47 Howard-Grabman L, Miltenburg AS, Marston C, et al. Factors affecting effective community participation in maternal and newborn health programme planning, implementation and quality of care interventions. BMC Pregnancy Childbirth 2017;17:268.
48 Abimbola S. Beyond positive a priori bias: reframing community engagement in LMICs. Health Promot Int 2020;35:598-609.

49 Deaton A, Cartwright N. Understanding and misunderstanding randomized controlled trials. Soc Sci Med 2018;210:2-21.

50 Neogi SB, Khanna R, Chauhan M, et al. Inpatient care of small and sick newborns in healthcare facilities. J Perinatol 2016;36:S18-23.

51 Nair N, Daruwalla N, Osrin D, et al. Community mobilisation to prevent violence against women and girls in eastern India through participatory learning and action with women's groups facilitated by accredited social health activists: a before-and-after pilot study. BMC Int Health Hum Rights 2020;20:6.

52 Fottrell E, Ahmed N, Morrison J, et al. Community groups or mobile phone messaging to prevent and control type 2 diabetes and intermediate hyperglycaemia in Bangladesh (DMagic): a cluster-randomised controlled trial. Lancet Diabetes Endocrinol 2019;7:200-12.

53 Jungo KT, Anker D, Wildisen L. Astana declaration: a new pathway for primary health care. Int J Public Health 2020;65:511-2.

54 Lahariya C, Roy B, Shukla A, et al. Community action for health in India: evolution, lessons learnt and ways forward to achieve universal health coverage. WHO South East Asia J Public Health 2020;9:82-91.

55 Odugleh-Kolev A, Parrish-Sprowl J. Universal health coverage and community engagement. Bull World Health Organ 2018;96:660-1. 